\title{
Costume Color: The Representation of Bangladeshi Tradition and Cultural Revival
}

\author{
SM Minhus ${ }^{1}$ and Liang Huie ${ }^{1,2 *}$ \\ ${ }^{1}$ Department of Textiles \& Clothing, Jiangnan University, China \\ ${ }^{2}$ Department of Art \& Design, Wuxi Institute of Arts \& Technology, China
}

*Corresponding author: Liang Huie, Professor, Department of Costume Culture and Fashion Design, Jiangnan University, China.

\begin{abstract}
The representation of traditional color in costumes is a unique phenomenon of cultural revival in Bangladesh. In order to explore the study context, seven colors were revealed as Bangladeshi traditional costume colors, namely- red, white, green, yellow, and orange, reddish-orange (r0), and orange-yellow (OY) from the theoretical concepts. Through the analytical method from the survey data, it was disclosed that the Bangladeshi traditional costume colors have a strong correlation and factor loading. Among all the mentioned colors, the main traditional costume colors were obtained from the color preference of different professional groups who participated in the survey process. Besides, the obtained main traditional costume colors have significant value and a strong impact on reviving the costume tradition in the modern-era that encourages further depth study.

Keywords: Bangladeshi tradition; Color concept; Costume; Cultural revival; Preference; Decorations
\end{abstract}

\section{Introduction}

Different cultures have their tradition and costume culture that represents a strong cultural existence from history to present by different cultural elements. Heritage frequently inspires contemporary fashion designers, yet they also make it modernize and reinvent traditional dress. From fashion history according to Stamper A. and Condra J [1], we can see how the human body has been dressed and decorated in every inferable way. The designer goes back to history for inspiration and fashion is the image of the past [2]. The traditional color concept is the way of provoking to keep the cultural ideology with modern society. Fashion must be impressionable to the combination of colors, shapes, lines, motifs, and designs for every historical time of art and costume [3,4]. At present, researchers have carried out in-depth research on patterns, functions, aesthetics, culture, and other aspects. They have only studied the surface color composition and a few regional color features in the field of "color", but not in the field of revealing the traditional color identification and protection. With the passage of time and the impact of the storage environment, the matrix material of the clothing collection in the archive is aging seriously [5], and the original color of clothing has changed but can recognize the color concept through different cultural activities.

Compared with unearthed cultural relics, although the time of modern clothing is only a few decades, it belongs to cultural relics to be protected [3]. We should pay attention to clothing closely related to people's lives, which has both technology and art. In the long run, its clothing preservation still has a great value [4]. From the time background, the modern clothing under the historical background of blending between different cultures height on dramatic shift, along with the invention of the modern western influence into culture [6], the research of this period costume color can reflect the particular social economy, social customs, and other factors. It also reflects Bangladeshi unique aesthetic 
taste, national character, and appropriate spiritual feelings. The modernization process of few decades has made traditional costumes into a collection and entered the museum [7]. Although the form and system of traditional costume have no reservation in current wearing, the aesthetic appreciation of traditional colors is still influencing Bangladeshi people's choice of modern costume colors imperceptibly, presenting a ubiquitous and much-hidden state. Therefore, the research on the color of modern folk clothing is helpful for us to grasp more clearly the change of the color aesthetic of the times and more accurately grasp the mainstream of the color aesthetic of the present generation [8]. Due to the formation and psychological structure of the traditional color aesthetics of Bangladesh conform to the spirit of the traditional culture, and the spiritual culture not only influences people's specific way of thinking, value orientation but also has a huge and far-reaching impact on the social psychology and behavior habit of the profound cultural aesthetic taste [9]. Therefore, not only from the traditional dress of the color image to find, more from the traditional way of thinking in the process of the color system formed to seeking the roots [10]. Bangladeshi color aesthetics is the product of various cultures, understandings, concepts, and colors that are different between regions.

This research discusses the Bangladeshi culture and traditional costumes as the research object and analyzes the color patterns and trends of Bangladeshi traditional clothing from the theory, interviews, and articles. These colors make Bangladeshi costumes significant in terms of tradition and cultural revival.

\section{Theoretical Concept}

\section{Cultural concept}

Bangladesh has a glorious intangible cultural heritage. Bangladeshi cultural heritage includes oral tradition, tribal art, folk arts and crafts, folk drama, folk songs, traditional aptitude, folk tales, folk games, folk healing, jokes, magic, proverbs, rituals, rhymes, the art of cooking, dress, religious festivals, place of residence, traditions and beliefs, customs and manners from where one can get the source of an idea about its cultural existence. We can have an idea about Bangladeshi traditional colors from different cultural existence and activities. In this article, the influence of traditional festival (Pohela Bishoakh - 'First day of Bengali new year', Falgun'First day month of spring', Hould- 'Part of pre-wedding function'), art (Alpana- 'Colourful motifs, sacred art or painting done with hands', Masks art) to give a concept about Bangladeshi color (Figure 1). From the art, designers can get visual inspiration about color, mood, or a certain spirit that looks to capture the time [11]. Designers from different countries such as Asiya Bareeva from Russia, Hwang Yi-Seul (Dew Hwang) from Korea, Iman Aldebe from Sweden, Jotaro Saito from Japan, Marwa Atik from California, Purvi Doshi from India used their inspiration from their cultural heritage. All modern fashion is the evolutionary reformation and outgrowth of the past fashion [12]. Bangladeshi people try to keep their tradition of costume either with their daily life or socio occasion in one way or another, and costume color is the key to concern with their styling also with the occasional theme. In every cultural festival have the reflection of traditional color concept in the form of costume, art or exhibit elements to represents the ethics of tradition. Every society has the norm of beauty. These are evidence for the best and the perfect expression of aesthetic appearance.

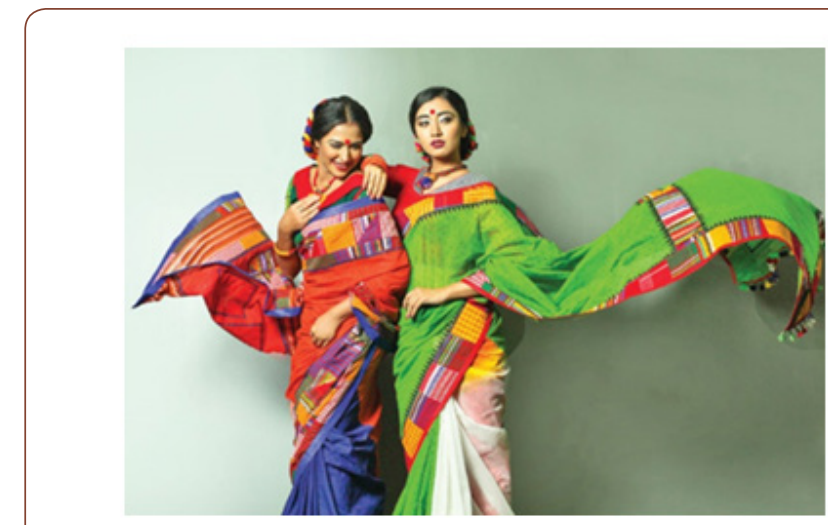

Figure 1: Costume of Pohela Boishakhi.

Kyung-Y Lee and Hoon Lee [13] discussed cultural values concerning traditional clothing and this research discussed Bangladeshi traditional colors. This survey adopts the method of the questionnaire to investigate the color preference of traditional clothing and its importance in the cultural Renaissance. Zhenjie Liao and Guangquan Dai [14], S Iran et al. studied with the context of culture and validate the dimensions of experience and examine various types of cultural factors. Domestic research on the development of Bangladeshi cultural clothing is based on traditional clothing. Based on traditional clothing, the research mainly focuses on clothing with ideological content. The research method is mainly to research the fashion aesthetic ideology and ancient clothing, which represents a monograph on the clothing culture of Bangladesh. Here will be introduced the history of traditional Bangladeshi costume color and briefly introduce the development history of Bangladeshi clothing. Traditional culture plays an important role in the progress and development of a country and can be inherited permanently, such as American Indian culture or Mayan culture. Each of them represents a country, even a country's history. Through the comparison of traditional costume colors and modern costume colors, understand the similarities and differences between them. The similarity between the two is to make better traditional costume concepts, but the difference is the design mode adopted. The development trend of the perfect integration of national culture and modern design concept not only inherits the good aspects of national cultural tradition but also creates the modern aesthetic concept.

\section{Costume color concept}

The difference between collective memory and cultural area is that collective memory is defined from the history of a group, that is, 
it is informal, and it conveys the historical significance and identity of a group in the past. The various aspects of the past constitute the elements of culture, which will persist as long as the culture is not replaced, and new cultures and traditions are absorbed $[15,16]$. Culture has a profound influence on social, national, and political life remains the most misunderstood human phenomenon in the development of esthetics in Bangladesh. In our constant quest for "excellence," Bangladeshi culture has hitherto been a littlecultivated and incubated force that drives basic human instincts: understanding, appreciation, and openness to the unknown [17]

The heritage festival of Bangladesh 'Pohela Boishakh' is one of the essential parts of the country's tradition, and the celebration of this festival makes people aesthetic in terms of costumes and decorations $[3,18]$. People wear special traditional costumes with a combination of red and white as well as sometimes with the influence of yellow and green colors for decoration purposes. A colorful procession holds as the part of that festival wearing colorful traditional costumes, makeup, tattoos in hand and face with red, white, and green colors traditional aesthetic patterns, holding banners of colorful masks and crafts that bear the presence of traditional colors. The celebration of the traditional festival 'Falgun'- the first day month of spring, gives the joys, colors, feelings of purity in the mind (Figure 2). People like to wear traditional costumes with floral motifs and patterns of yellow, orange, as well as the presence of red such as reddish-orange. The women like to decorate themselves with fresh flowers as a symbolic messenger for the new generation to remind the root of culture and tradition.

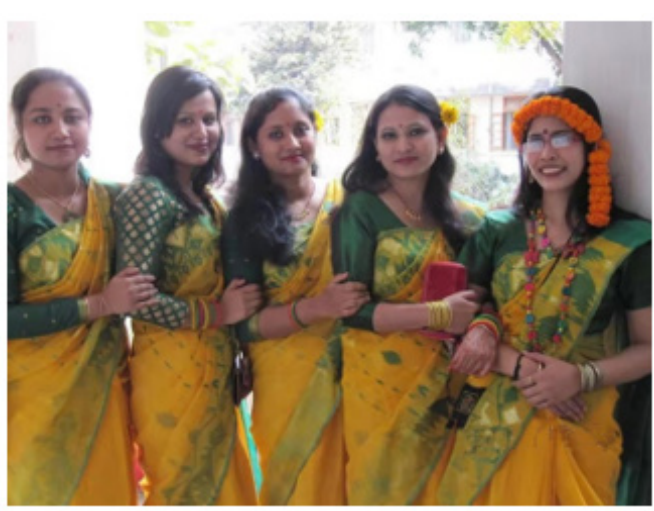

Figure 2: Costume of Falgun celebration.

The celebration of 'Holud'- part of the pre-wedding festival, keeps the tradition of costume tradition, and the trend of this function comes from generation to generation. Special costume with yellow, orange-yellow as well as with the combination of red color makes this function aesthetic with auspicious traditional meaning with the blessing for both bride and groom (Figure 3). The traditional festivals and functions that come from history represent the existence of its tradition. From the theory of Bangladeshi traditional representative elements, books reviews, interviews author assumed red, white, green, yellow, orange, rO, and OY as Bangladeshi traditional costume colors, and this concept can be hypothesized that mentioned colors have a strong impact on Bangladeshi traditional costume and for a cultural revival.

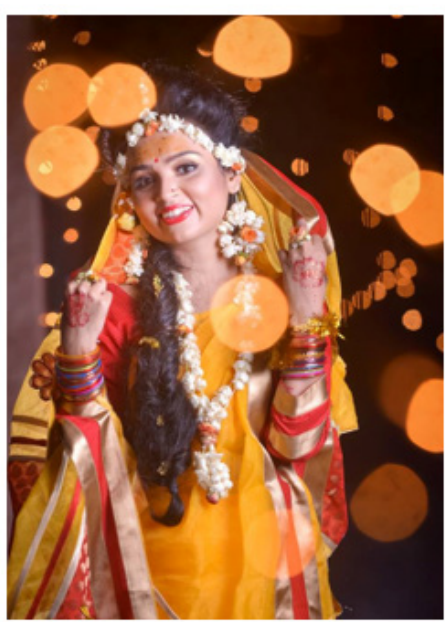

Figure 3: Costume of a pre-wedding occasion (Holud).

H1. The assumed traditional costume colors (red, white, green, yellow, orange, rO, OY) have a positive impact on Bangladeshi culture and that enhances the significance of cultural revival.

\section{Methodology}

\section{Constitution of data}

To analyze the Bangladeshi traditional costume color, firstly measured items were derived from the theoretical concepts that related to colors and their significance. Measured variable questions about the red, white, green, yellow, orange, rO, and OR colors as the representatives of traditional costumes color and research significance. The questionnaires prepared with a five-point Likert scale for the survey as well as had questions about which colors are selected as the main traditional costume colors from given color by the participants and also had a survey about their interest in traditional costume diversifications and the way of cultural revival.

\section{The scale of samples}

A total of 308 participants' opinions were obtained from 350 distributed data surveys and usable data rates of $88 \%$. All survey data collected from the participants of Bangladeshi nationalities and within selected five professions design students, educationalists, designers, people in business, and journalists For the SPSS analysis, the survey report converted into a data coding system.

\section{Techniques of data analysis}

From the survey, data first analyzed the demographic characteristics of participants through descriptive data analysis. Then performed exploratory factor analysis to evaluate survey values regarding assumed costume colors, and Cronbach's alpha was performed to analyze the internal consistency of respondents about traditional costume color. After that, descriptive analysis was performed to analyze the result of the main costume colors. Finally, the significance of Bangladeshi main traditional costume color 
among designers, educationalists, design students, businessmen, and journalists were analyzed using a one-way ANOVA.

\section{Result Analysis}

The survey participants were from Bangladesh: among them, $57.1 \%$ were female and $42.9 \%$ were male. Most of the participants were single (65\%) and age between $20-29$ years (50.6\%); others were $<19$-(17.9\%), 30-39 (19.5\%), 40-49 (7.1\%), and above 50 years old (4.9\%). Among the participants, design students (47.1\%), and other professions are educationalists (14.2\%), designers (10.6\%), businessmen (13.2\%), and journalists (14.8\%) (Table 1).
This result from all 308 respondents and data items were tested by performing exploratory factor analysis (EFA). The variable items that express Bangladeshi traditional costume colors were explained by performing EFA selecting correlation matrix and varimax rotation with principal component analysis method. To ensure a good correlation among the variable items, less than 0.4 -factor loading was deleted [19]. From table 2, the Kaiser-MeyerOlkin measure $=0.909$, Bartlett's test of sphericity: $\chi 2=3145.745$ ( $p<0.001$ ) that are highly acceptable for this study because participants of data survey more than 300 [20].

Table 1: Demographic characteristics of participants.

\begin{tabular}{|c|c|c|c|c|c|}
\hline \multicolumn{6}{|c|}{ Total Number of Participant $(\mathrm{N}=\mathbf{3 0 8}$ ) } \\
\hline & Frequency & Percent (\%) & & Frequency & Percent (\%) \\
\hline Gender & & & Marital status & & \\
\hline Male & 132 & 42.9 & Single & 203 & 65.9 \\
\hline Female & 176 & 57.1 & Married & 105 & 34.1 \\
\hline Age & & & Occupation & & \\
\hline Under 19 & 55 & 17.9 & Student & 146 & 47.1 \\
\hline $20-29$ & 156 & 50.6 & Educationalist & 44 & 14.2 \\
\hline $30-39$ & 60 & 19.5 & Designer & 33 & 10.6 \\
\hline $40-49$ & 22 & 7.1 & Businessman & 41 & 13.2 \\
\hline Above 50 & 15 & 4.9 & Journalist & 44 & 14.8 \\
\hline
\end{tabular}

To analyze the reliability and internal consistency of data variables, Cronbach's alpha was analyzed for each item and Table 2 , showing a total Cronbach's $\alpha=0.920$ that were highly acceptable because of value higher than 0.7 [21]. A total of $78.515 \%$ variance explained in this analysis as well are the significance of this study also supported because of high factor loading and Cronbach's alpha value and that shows the assumption of Bangladeshi traditional costume colors are acceptable by the respondents. These results proved that the hypothesis was supported for this study.

Table 2: The measurement from the exploratory factor analysis and reliability test.

\begin{tabular}{|c|c|c|c|}
\hline $\mathbf{s}$ & Factor loading $(\lambda)$ & P-value & Cronbach's $\alpha$ \\
\hline Red & 0.891 & $.000^{* * *}$ & 0.899 \\
\hline White & 0.826 & $.000^{* * *}$ & 0.9 \\
\hline Green & 0.88 & $.000^{* * *}$ & 0.902 \\
\hline Yellow & 0.914 & $.000^{* * *}$ & 0.898 \\
\hline Orange & 0.846 & $.000^{* * *}$ & 0.901 \\
\hline Reddish-orange(rO) & 0.51 & $.000^{* * *}$ & 0.928 \\
\hline Orange-yellow (OY) & 0.917 & $.000^{* * *}$ & 0.898 \\
\hline Significance & 0.79 & $.000^{* * *}$ & 0.941 \\
\hline \multicolumn{4}{|c|}{ 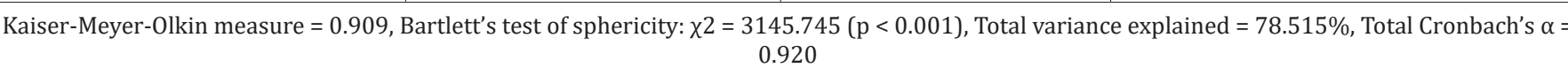 } \\
\hline
\end{tabular}

\section{Result Analysis for Bangladeshi Main Traditional} Costume Colors

Table 3, SPSS analysis shows descriptive results of the main traditional colors (in percentage) among red, white, green, yellow, orange, rO, and OY. Also given analysis separated according to participant's profession- student, educationalist, designer, businessman, and journalist. From Table 3, the main traditional colors by rank were determined as follows: red (100\%), white (55\%), green (59\%) whether other colors were not selected as the main traditional costume color. There is a high ratio in red color, 
and 10 participants mentioned red as Bangladeshi main traditional costume color. From the participants separately color preference was determined as follows: among students- red (100\%) > green $(69 \%)>$ white $(53 \%)$, among educationalists- red $(100 \%)>$ white $(73 \%)>$ green $(50 \%)$, among designers- red $(100 \%)>$ white $(70 \%)>$ green $(30 \%)$, among businessmen- red $(100 \%)>$ green
$(56 \%)>$ white $(44 \%)$, among journalists- red $(100 \%)>$ green $>(61 \%)>$ white $(40 \%)$. From the overall ratio red, white, and green are Bangladeshi main traditional costume colors among all professional's participants though white and green had noticeable differences compare to red color.

Table 3: Descriptive analysis (percentage) of Bangladeshi main traditional costume colors.

\begin{tabular}{|c|c|c|c|c|c|c|c|c|}
\hline \multicolumn{2}{|c|}{ Occupation } & \multirow{2}{*}{$\begin{array}{c}\text { Red } \\
1 \\
\end{array}$} & \multirow{2}{*}{$\begin{array}{c}\text { White } \\
0.53\end{array}$} & \multirow{2}{*}{$\begin{array}{c}\text { Green } \\
.69\end{array}$} & \multirow{2}{*}{$\begin{array}{c}\text { Yellow } \\
0\end{array}$} & \multirow{2}{*}{$\begin{array}{c}\text { Orange } \\
0\end{array}$} & \multirow{2}{*}{$\begin{array}{c}\text { ro } \\
0\end{array}$} & \multirow{2}{*}{$\begin{array}{c}\text { OY } \\
0\end{array}$} \\
\hline Student & Mean & & & & & & & \\
\hline & $\mathrm{N}$ & 146 & 146 & 146 & 146 & 146 & 146 & 146 \\
\hline & Std. Deviation & 0 & 0.501 & 0.463 & 0 & 0 & 0 & 0 \\
\hline \multirow[t]{3}{*}{ Educationalist } & Mean & 1 & 0.73 & 0.5 & 0 & 0 & 0 & 0 \\
\hline & $\mathrm{N}$ & 44 & 44 & 44 & 44 & 44 & 44 & 44 \\
\hline & Std. Deviation & 0 & 0.451 & 0.506 & 0 & 0 & 0 & 0 \\
\hline \multirow[t]{3}{*}{ Designer } & Mean & 1 & 0.7 & 0.3 & 0 & 0 & 0 & 0 \\
\hline & $\mathrm{N}$ & 33 & 33 & 33 & 33 & 33 & 33 & 33 \\
\hline & Std. Deviation & 0 & 0.467 & 0.467 & 0 & 0 & 0 & 0 \\
\hline \multirow[t]{3}{*}{ Businessmen } & Mean & 1 & 0.44 & 0.56 & 0 & 0 & 0 & 0 \\
\hline & $\mathrm{N}$ & 41 & 41 & 41 & 41 & 41 & 41 & 41 \\
\hline & Std. Deviation & 0 & 0.502 & 0.502 & 0 & 0 & 0 & 0 \\
\hline \multirow[t]{3}{*}{ Journalist } & Mean & 1 & 0.4 & 0.61 & 0 & 0 & 0 & 0 \\
\hline & $\mathrm{N}$ & 44 & 43 & 44 & 44 & 44 & 44 & 44 \\
\hline & Std. Deviation & 0 & 0.495 & 0.493 & 0 & 0 & 0 & 0 \\
\hline \multirow[t]{3}{*}{ Total } & Mean & 1 & 0.55 & 0.59 & 0 & 0 & 0 & 0 \\
\hline & $\mathrm{N}$ & 308 & 307 & 308 & 308 & 308 & 308 & 308 \\
\hline & Std. Deviation & 0 & 0.499 & 0.492 & 0 & 0 & 0 & 0 \\
\hline
\end{tabular}

For the comparison and to show the significant value of the traditional costume color preference between students, educationalists, designers, businessmen, and journalists, the oneway ANOVA was performed. The result of data analysis showed that there was a statistical difference in white $(\mathrm{F}=3.819, \mathrm{P}<0.01)$, green $(\mathrm{F}=5.048, \mathrm{P}<0.01)$. There was no statistical difference for red

color because all participants selected red as the main traditional costume color and the result of the analysis is shown in Table 4. The values were calculated between the professional groups. Therefore, red, white, and green are significant as the main traditional costume color from the overall analytical process.

Table 4: One-way ANOVA test of Bangladeshi main traditional costume color preference.

\begin{tabular}{|c|c|c|c|c|c|c|}
\hline & & Sum of Squares & df & Mean Square & F-value & Sig. (P) \\
\hline \multirow[t]{3}{*}{ Red } & Between Groups & 0 & 4 & 0 & . & . \\
\hline & Within Groups & 0 & 303 & 0 & & \\
\hline & Total & 0 & 307 & & & \\
\hline \multirow[t]{3}{*}{ White } & Between Groups & 3.663 & 4 & 0.916 & 3.819 & $.005^{* *}$ \\
\hline & Within Groups & 72.402 & 302 & 0.24 & & \\
\hline & Total & 76.065 & 306 & & & \\
\hline \multirow[t]{3}{*}{ Green } & Between Groups & 4.64 & 4 & 1.16 & 5.048 & $.001^{* *}$ \\
\hline & Within Groups & 69.629 & 303 & 0.23 & & \\
\hline & Total & 74.269 & 307 & & & \\
\hline
\end{tabular}




\section{Discussion}

This research first discussed the overview of Bangladeshi traditional costume colors and the field of traditional color concepts that have a substantial impact on this study. The main purpose is that assumed color from the theoretical analysis influence Bangladeshi traditional costume, measured among the survey participants from Bangladesh. To analyzed this result first shown the relationship between survey data of item variables that were selected for costume color. Then analyzed the main traditional costume color from all assumed colors and find out the significant value of the main colors.

From the analysis, traditional costume colors red, white, green, yellow, orange, rO, and OR has a high internal correlation and reliability that shown the assumed costume colors are significant for this study. After that, from all assumed colors, three main colorsred, white, and green are finalized for traditional costume colors that had more significant values. The result analyzed that there are different preferences of Bangladeshi traditional colors compared with different professional's people and the main colors are examined. In order to realize the communion of cultural costume elements in modern fashion design, cultural costume elements like modeling, color, pattern, fabric and crafts, and other elements have to be connected with modern aesthetic psychology and design rules, and then the design researcher provides innovative design and blends cultural costume elements and modern design elements together. Besides, for innovative ideas, researchers would give a new understanding and explanation of cultural elements on the basis of the modern version to make the works not only reflect traditional costume culture, with the functional needs and aesthetic psychology of the modern generation. Moreover, the researchers should study integrating national and modern elements together so that the essence of traditional and modern culture can melt and collide with each other to develop harmoniously.

The impact of colors in traditional costumes refers to the identity for cultural revival as this costume color symbolizes the auspicious meaning for tradition from history. The traditional occasions with identical costume colors give the reference of significance to retain the tradition in this way. This phenomenon of revival is creating a new stage of cultural change that relates to traditional values of globalization and the effect of national development has an impact on it. The tendency to keep traditional elements in new forms of affinity for cultural revival with new ideas can make a mind of cultural revaluation.

\section{Conclusion}

The overall analytical ratio of Bangladeshi traditional costume color preference was not statistically different among different professions. The mentioned hypothesis gives a depth understanding of the logical part of the study context. All assumed colors have an impact on Bangladeshi traditional costumes throughout the years. From the above analytical discussion, red is Bangladeshi main traditional costume color as well as white and green that is not significantly much different. Though in the analysis compared among separated groups, resulting in the variation that is negligible for the overall result analysis. Compare with white and green, the preference for yellow was not negligible as a traditional color. These color combinations with traditional patterns can use in contemporary fashion to revive traditional aestheticism.

Since the scope of this study was limited among the several professional participants and their opinions, the findings of this study cannot be negligible compared to overall Bangladeshi citizen's thinking and their attire in different cultural festivals. Further research may analyze the details of color hue and variation in different traditional costumes that might give more detailed information about Bangladeshi traditional color concepts.

\section{Funding}

This research was funded by the Major Projects of Philosophy and Social Sciences Foundation of the Jiangsu Higher Education Institutions of China (Grant No. 2019SJZDA021).

\section{Acknowledgment}

The author would like to thanks Omor Munna (Photographer) and Nushrat Yiasmin for their photos. Also, acknowledge the survey participants from Bangladesh who spent their valuable time answering the questionnaires sincerely.

\section{Conflict of Interest}

The author declares no conflict of interest.

\section{References}

1. Stamper A, Condra J (2011) Clothing through American History: The Civil War through the Gilded Age, 1861-1899. Santa Barbara, California: Greenwood, USA.

2. Mougenot C, Bouchard C, Aoussat A (2008) Inspiration, images and design : an investigation of designers' information gathering strategies. Journal of Design Research 7(4): 331-351.

3. Min S, Koo H (2017) Sustainable apparel design strategies regenerated from traditional costumes of the Chosun Dynasty. Research Journal of Textile and Apparel 21(1): 27-41.

4. Sohn M, Dong-Eun K (2016) Conceptual Clothinsg Design Process Using Cooperative Learning Strategies: Senior Clothing Design Class. Fashion, Industry and Education 14(1): 59-68.

5. Koo HS, Dunne L, Bye E (2013) Design functions in transformable garments for sustainability. International Journal of Fashion Design, Technology and Education 7(1): 10-20.

6. Miller-Spillman KA (2013) Fashion and fantasy. In K. A. Miller-Spillman, A Reilly, P. Hunt-Hurst Meanings of Dress, $3^{\text {rd }}$ edn, New York: Fairchild Books, USA.

7. Burnett C (2015) Under the Auspices of Simplicity: Roger Leenhardt's New Realism and the Aesthetic History of Objectif 49. Film History: An International Journal 27(2): 33-75.

8. Bortoli MD, Maroto J (2001) Colors Across Cultures: Translating Colors in Interactive Marketing Communications. in European Languages and the Implementation of Communication and Information Technologies (Elicit) Conference. University of Paisley.

9. Volpintesta L (2014) The language of fashion design : 26 principles every fashion designer should know. Beverly: Rockport Publishers. 223. 
10. Shin MJ, Westland S, Moore EM, Cheung V (2012) Colour preferences for traditional Korean colours. Journal of the International Colour Association 9: 48-59.

11. Frings GS (1991) Fashion from concept to consumer $3^{\text {rd }}$ edn, New Jersey: Prentice Hall, USA.

12. Sproles GB, Burns LD (1994) Changing Appearances: Understanding Dress in Contemporary Society New York: Fairchild Publications, USA.

13. Lee KY, Lee H (2019) Traditional costume experience at a cultural heritage festival. Tourism Management Perspectives. 32.

14. Liao Z, Dai G (2020) Inheritance and Dissemination of Cultural Collective Memory: An Analysis of a Traditional Festival. Sage publication.

15. LeeH, Hwang H, Shim C (2019) Experiential festival attributes, perceived value, satisfaction, and behavioral intention for Korean festivalgoers. Tourism and Hospitality Research 19(2): 199-212.

16. Mbonu E (2014)Fashion design research London: Laurence King Publishing Ltd, England.
17. Haque M (2001) Bangladesh 2001: The Myth of Bengali Culture in HOLIDAY: Dhaka, Bangladesh.

18. Khalid MS, Alam Chowdhury MS (2018) Representation of intangible cultural heritage of Bangladesh through social media. Anatolia 29(2): 194-203.

19. Maeng HY, Jang HY, Li JM (2016) A critical review of the motivational factors for festival attendance based on meta-analysis. Tourism Management Perspectives 17: 16-25.

20. Field A (2013) Discovering Statistics Using IBM SPSS Statistics. Forth ed., Los Angeles: SAGE publication.

21. Cortina JM (1993) What is coeficient alpha? An examination of theory and applications. Journal of Applied Psychology 78(1): 98-104. 